\title{
O PELC-Povos e comunidades tradicionais e a formação de professores do CEFD
}

\author{
PELC-People and traditional communities and CEFD teacher training
}

El PELC-Pueblos y comunidades tradicionales y la formación de los profesores del CEFD

Tatiane Rocha Razeira ${ }^{\mathrm{I}}$, Rosane Lorentz Castilhos ${ }^{\mathrm{II}}$, Sabrine Damian Da Silva ${ }^{\mathrm{III}}$, Roberta Bevilaqua de QuadrosI ${ }^{\mathrm{VI},}$ Rosalvo Luís Sawitzki ${ }^{\mathrm{V}}$

\begin{abstract}
Resumo
O presente estudo objetiva compreender de que modo a experiência de atuação como agente social do PELC/PCT/UFSM repercutiu na formação inicial dos acadêmicos de Educação Física do Centro de Educação Física e Desportos. A pesquisa possui cunho qualitativo e constitui-se como estudo de caso. Foram realizadas entrevistas semiestruturadas com acadêmicos de Educação Física participantes do Programa, posteriormente, as entrevistas foram analisadas pelo método de análise de conteúdo. Percebeu-se, como legados do Programa frente à formação inicial dos acadêmicos: a busca por novos aprendizados e a interligação entre conhecimentos teóricos e práticos; a necessidade de desenvolver durante o processo formativo a interligação entre o aprendizado acadêmico e a realidade social vivida fora deste âmbito; a possibilidade de compreender as pessoas participantes quanto às suas individualidades; e também a percepção de um campo de atuação com as pessoas idosas.
\end{abstract}

Palavras-chave: Formação; Educação Física; Comunidades Rurais

\begin{abstract}
This study aims to understand how the experience of acting as a social agent of the PELC/PCT/UFSM had repercussions on Physical Education initial formation at Physical Education and Sports Center. The research is qualitative and it constitutes a case study. Semi-structured interviews were conducted with Physical Education students participating in the Program, and later the interviews were analyzed using the content analysis method. It was noticed, as legacies of the Program in face of the initial training of academics, the search for new learning and the interconnection between theoretical and practical knowledge; the need to develop, during the formative process, the interconnection between academic learning and the social reality lived outside this scope; the possibility of understanding the participating people as to their individualities; and also the perception of a field of action with the elderly.
\end{abstract}

Keywords: Formation; Physical Education; Rural Communities

${ }^{\text {I } P o n t i f i ́ c i a ~ U n i v e r s i d a d e ~ C a t o ́ l i c a ~ d o ~ R i o ~ G r a n d e ~ d o ~ S u l, ~ P o r t o ~ A l e g r e ~-~ P U C R S ~-~ E n d e r e c ̧ o: ~ R u a ~ E x p e d i c i o n a ́ r i o ~ A l m e i d a ~ 65 / 302, ~ C E P: ~ 97400000 ~ S a ̃ o ~ P e d r o ~}$ do Sul, RS - e-mail: tatirazeira@gmail.com

${ }^{\text {II }}$ Universidade Federal de Santa Maria - UFSM - e-mail: rosane cast@yahoo.com.br

III Universidade de Lleida, Espanha - e-mail: sabrinedamian@hotmail.com

VI Universidade Federal de Santa Maria - UFSM - e-mail: robertabevilaqua@ hotmail.com

${ }^{v}$ Universidade Federal de Santa Maria - UFSM - e-mail: rosalvols@ hotmail.com 


\section{Resumen}

Este estudio tiene como objetivo comprender de qué modo la experiencia de actuar como agente social del Programa de Esporte e lazer na Cidade - PELC/PCT/UFSM repercutió en la formación inicial de los académicos de Educación Física del Centro de Educación Física y Deportes. La investigación tiene carácter cualitativo y es un estudio de caso. Fueran realizadas entrevistas semiestructuradas con alumnos de educación física participantes del Programa. Posteriormente las entrevistas fueran analizadas por el método de análisis de contenido. Se percibió como legado del Programa en relación con la formación inicial de los alumnos: la búsqueda de nuevos aprendizajes y la interconexión entre los conocimientos teóricos y prácticos; la necesidad de desarrollar durante el proceso formativo, la interconexión entre el aprendizaje académico y la realidad social vivida fuera de este ámbito; la posibilidad de comprender a las personas participantes en cuanto a sus individualidades; y también la percepción de un campo para actuar con los ancianos.

Palabras clave: Formación; Educación Física; Comunidades rurales

\section{Introdução}

Ao abordar nesse trabalho o Programa Esporte e Lazer da Cidade - Povos e Comunidades Tradicionais (PELC/PCT), caracterizado como uma política pública de governo, não se pode deixar de reportar inicialmente a nossa Constituição Federal de 1988, que traz em seu artigo 217 a definição de que é dever do Estado: "promover práticas desportivas formais e não formais", e complementa com o parágrafo $3^{\circ}$, “o incentivo ao lazer como forma de promoção social” (BRASIL, 2002, p.132).

As políticas públicas são diretrizes que buscam a resolução de problemas ligados à sociedade de maneira geral. Podem ser entendidas como ações voltadas para a garantia dos direitos sociais, configurando um compromisso público que vise determinada situação em áreas diversas (SOUZA, 2006). Foi nessa perspectiva que, no ano de 2003, o Ministério do Esporte $^{1}$ por intermédio da extinta Secretaria Nacional de Desenvolvimento do Esporte e Lazer (SNDEL), e que hoje é representada pela Secretaria Nacional de Esporte, Lazer e Inclusão Social (SNELIS), criou o Programa Esporte e Lazer da Cidade (PELC).

O PELC tinha como finalidade proporcionar a prática de atividades físicas, culturais e de lazer que abarcassem todas as faixas etárias e pessoas com deficiência, envolvendo diferentes setores da administração pública e gestores comunitários, assim como estimular a convivência social, a formação de gestores e lideranças comunitárias, favorecendo a pesquisa e a socialização do conhecimento, contribuindo para que o esporte e lazer fossem tratados como políticas e direitos de todos (BRASIL, 2012).

\footnotetext{
${ }^{1}$ Em 2019 o presidente Jair Messias Bolsonaro extingue o Ministério do Esporte, incorporando-o ao Ministério da Cidadania como Secretaria Especial do Esporte.
} 
O programa disponibilizou três ${ }^{2}$ organizações internas, onde cada uma é específica para os públicos a serem contemplados nos convênios. Neste caso, debruçamo-nos sobre a realidade do PELC direcionado aos Povos e Comunidades Tradicionais (PCT), como mencionado a princípio, assim designado pelo Ministério do Esporte:

[...] Tem seu foco nos grupos culturalmente diferenciados e que se reconhecem como tal por possuírem formas próprias de organização social e ocuparem territórios tradicionais. Assim, são comunidades tradicionais: povos indígenas, quilombolas, populações ribeirinhas, populações rurais, dentre outras. (BRASIL, 2012, p. 3).

Esta especificidade para PCT foi implementada e desenvolvida através de convênio entre o Ministério do Esporte (ME) e a Universidade Federal de Santa Maria (UFSM), e com o apoio do Centro de Educação Física e Desportos (CEFD), no período entre março de 2013 e dezembro de 2014. Nessa instituição foi executado como um projeto de extensão registrado no Gabinete de Projetos $\left(\mathrm{n}^{\circ}\right.$ projeto 032914), intitulado "Programa Esporte e Lazer da Cidade - núcleos para os povos e comunidades tradicionais - povos indígenas, quilombolas, populações Ribeirinhas, populações rurais, dentre outras todas as faixas etárias”. Essa nomenclatura é a do Ministério do Esporte e que foi adaptada para fins de adequar o nome às populações atendidas, sendo utilizado "Programa Esporte e Lazer da Cidade para Povos e Comunidades Tradicionais: Quilombolas e Rurais"3. O Programa teve como sistemática de trabalho a organização em dois Núcleos ${ }^{4}$, sediados nos municípios de Santa Maria - RS e Restinga Seca RS, respectivamente o Núcleo Palma e o Núcleo Restinga Seca.

Os locais de atuação foram três quilombos e vinte e quatro comunidades rurais destes dois municípios, totalizando um número de 1.114 pessoas inscritas em suas oficinas, que ocorriam com periodicidade entre uma e duas vezes por semana, mediante os planejamentos e atuações dos agentes sociais $^{5}$ nestas comunidades.

No total atuavam no programa doze agentes sociais, sendo seis em cada núcleo, dentre os quais acadêmicos do CEFD dos cursos de Educação Física (licenciatura e bacharelado) e Dança, e também do curso de Música da UFSM. A carga horária semanal era de 20 horas, utilizada com planejamentos das oficinas, avaliação das mesmas, entrega de relatórios mensais à coordenação sobre suas atividades, organização dos espaços junto às comunidades, participação nas formações do Ministério do Esporte e

\footnotetext{
${ }^{2}$ A organização do PELC foi feita em três núcleos: Vida Saudável, Todas as Idades e para Povos e Comunidades TradicionaisQuilombolas e Rurais.

${ }^{3}$ Utilizaremos a sigla PELC/PCT/UFSM para se referir ao Programa Esporte e Lazer da Cidade para Povos e Comunidades Tradicionais: Quilombolas e Rurais, desenvolvido pela Universidade Federal de Santa Maria.

${ }^{4}$ Denominação utilizada pelo Ministério do Esporte que define como Núcleos as regiões que abrangem as localidades que os PELCs desenvolvem suas ações de esporte e lazer.

${ }^{5}$ Denominação do Ministério do Esporte aos responsáveis por desenvolver as atividades de esporte e lazer com as pessoas das comunidades.
} 
nas organizadas internamente pela coordenação, reuniões de planejamento e estudos, bem como orientação, organização e participação em eventos festivos nas comunidades.

As oficinas e/ou atividades, como eram nomeadas pelo Ministério do Esporte, ocorriam uma a duas vezes por semana, e contemplavam a cultura corporal e lúdica de acordo com as características e interesses das comunidades (jump, esportes, danças, ginásticas, alongamento, artesanato), em locais cedidos por elas (como salões, escolas, campos, ginásios e até necrotérios) e em dias e horários sugeridos pela comunidade, buscando adaptar com a disponibilidade dos acadêmicos e abranger o maior número de pessoas.

É importante ressaltar a implantação do PELC/PCT/UFSM no CEFD como um projeto de extensão, já que esse foi pioneiro no que tange ao público alvo e aos vários setores envolvidos no seu desenvolvimento, além disso, proporcionou aos estudantes um profícuo campo de atuação e de produção de conhecimentos e pesquisas, sendo identificado que muitos dos acadêmicos que participaram do projeto fizeram seus trabalhos de conclusão de curso com pesquisas realizadas a partir dessa experiência e aprendizado.

Os agentes sociais, por serem acadêmicos, são atores do processo de formação inicial de professores. Cabe destacar Carreiro da Costa (1994, p. 27), que expõe a formação inicial como o "período durante o qual o futuro professor adquire os conhecimentos científicos e pedagógicos e as competências necessárias para enfrentar adequadamente a carreira docente", sendo um tema enfatizado em vários estudos e por autores importantes da área educacional.

Em relação à formação inicial, o ponto norteador são os saberes docentes, ressaltados na obra de Tardif (2014), que os conceitua como diversos saberes provenientes de diferentes fontes. Essa conceituação compreende-se por meio do entendimento de que os saberes docentes se classificam em quatro ramificações, sendo os saberes da formação profissional, os saberes disciplinares, os saberes curriculares e os saberes experienciais, mostrando a sua multiplicidade.

O estímulo para participação de acadêmicos em projetos de extensão, segundo Rechia, Tschoke e Moro (2012), é uma prática relacionada mais às universidades públicas, devido, também, ao fato de se nortearem pelo tripé ensino-pesquisa-extensão. A extensão mostra-se como um fator presente na rotina acadêmica junto com a pesquisa e o ensino, como destacam Chaves e Gamboa (2008, p. 145), que entendem a mesma como "processo educativo, cultural e científico que articula o ensino e a pesquisa de forma indissociável e viabiliza a relação transformadora entre universidade e sociedade".

As ações de cunho extensionista, segundo o Projeto Pedagógico Institucional da UFSM, universidade que abarca as ações extensionistas aqui tratadas, são indissociáveis do ensino e da pesquisa quando queremos promover a formação integral do estudante. Também se reconhece que a articulação 
entre esses três elementos "auxilia a vislumbrar perspectivas e soluções mais amplas e criativas para as demandas sociais, além de incentivar uma sólida formação profissional.” (UFSM, 2016, p.156).

O programa desenvolvido no CEFD foi implementado por meio de convênio entre o Ministério do Esporte e a UFSM. Deve-se destacar aqui que o projeto enviado para o Ministério do Esporte para disputar o edital foi escrito por acadêmicas do CEFD sob orientação de um professor titular, e ficou em primeiro lugar entre os projetos enviados pelas Universidades de todo Brasil, e, além disso, cumpriu o prazo de vigência e foi renovado devido à ótima gestão dos recursos e várias parcerias realizadas.

$\mathrm{Na}$ esteira desses conhecimentos, essa pesquisa objetiva compreender os legados construídos frente à formação inicial a partir da atuação de acadêmicos de Educação Física do CEFD no PELC/PCT/UFSM.

\section{Metodologia}

Esse estudo caracteriza-se como pesquisa de cunho qualitativo e constitui-se em um estudo de caso, que, segundo Martins (2006), é um mergulho profundo e exaustivo em um objeto delimitado, possibilitando a imersão em uma realidade social, que somente através de um levantamento amostral ou avaliação quantitativa não seria possível chegar a esta realidade. Outra característica importante do estudo de caso é a flexibilidade, visto que não exige roteiro rígido, tornando possível realizar adequações necessárias para o melhor andamento do estudo durante o processo (GIL, 1987).

Para estruturar o grupo de participantes, dois critérios de inclusão foram utilizados. O primeiro era ter atuado como agente social por no mínimo dezoito meses, para que, através deste período mais extenso de trabalho nas comunidades, o agente social detivesse maior interação junto ao Programa. O segundo era ter essa atuação realizada simultaneamente em comunidades quilombolas e rurais, dispondo de conhecimentos sobre ambas as realidades de atuação. Com base nesses critérios, o grupo de participantes foi composto por cinco acadêmicos do curso de Licenciatura em Educação Física.

Com o grupo especificado, no momento dos diálogos onde ocorreu a produção de fontes de pesquisa $^{6}$, utilizou-se como instrumento entrevista semiestruturada, pois essa ferramenta pode ser vista como "uma conversa a dois ou entre vários interlocutores, realizada por iniciativa do entrevistador. Pois a mesma tem por objetivo construir informações pertinentes para um objeto de pesquisa" (MINAYO, 2012, p. 64).

\footnotetext{
${ }^{6}$ A escolha pelo uso do termo fontes de pesquisa para nos referirmos ao momento dos diálogos realizados nas entrevistas com os participantes deu-se através de nosso afeiçoamento com o mesmo, através de leituras e durante a apreciação dos diálogos com as pessoas entrevistadas, passamos a perceber que não foram somente coletados dados ou informações e sim esses momentos constituíram as fontes do estudo, influenciando-o na totalidade e não somente no momento das análises.
} 
Nesse tipo de entrevista se assegura que o informante tenha liberdade e espontaneidade necessárias para expressar-se sem estar moldado por questões formuladas, assim como o entrevistador pode estar à vontade para aprofundar em questões que podem surgir durante os diálogos. As entrevistas semiestruturadas foram realizadas de forma individual nas instalações do CEFD.

Posteriormente, as entrevistas foram transcritas e, com as autorizações de fidedignidade, foram analisadas através do método de análise de conteúdo baseado em Franco (2012, p.25), que é apresentado como "um procedimento da pesquisa que se situa em um delineamento mais amplo da teoria da comunicação e tem como ponto de partida a mensagem”.

\section{Resultados e discussão}

Durante o PELC/PCT/UFSM, foram realizados pelo Ministério do Esporte três Módulos de Formação (Introdutório; Aprofundamento; Avaliação), assim como, foram realizadas Formações em Serviço (reuniões pedagógicas, grupo de estudos, relato de experiência, etc), organizadas internamente pela coordenação do PELC/PCT/UFSM juntamente com os agentes sociais. Sobre as formações do Ministério do Esporte, Deise, Jaqueline, Fernando, Yara e Laura ${ }^{7}$ destacaram que, apesar de serem bem programadas pela formadora, algumas vezes existia a necessidade de algumas alterações do seu planejamento durante o desenvolvimento: “As Formações do Ministério nos ajudaram bastante, mas o que atrapalhou um pouco foi que a formadora estruturava as formações baseada nas realidades rurais e quilombolas lá de Goiás, aí não fechava com o que trabalhávamos aqui [...]” (Laura).

Já nas Formações em Serviço, que eram organizadas pela coordenação do Programa, onde os pontos a serem desenvolvidos eram delimitados juntamente com os agentes sociais, Jaqueline, Laura e Deise expressaram mais incisivamente suas percepções quanto à posição de proximidade da coordenação: "como o pessoal estava sempre nos acompanhando nas oficinas, sabiam muito bem quais eram nossas dificuldades nas comunidades e, a partir disso, organizavam as formações, aí era específico pro nosso grupo" (Deise).

Os agentes sociais do PELC/PCT/UFSM desenvolviam suas ações nas comunidades (oficinas/atividades), onde se estabeleceram relações de proximidade com os membros de cada localidade, o que proporcionava, além de desenvolver as atividades/oficinas propriamente ditas, também um papel político, pois esses agentes sociais tinham a "possibilidade de protagonizar momentos de mudanças, em uma nova relação social entre os sujeitos" (TONDIN, 2011, p. 46).

\footnotetext{
${ }^{7}$ Foram utilizados nomes fictícios para referir-se aos agentes entrevistados.
} 
Dessa forma, essa atuação provocou mudanças e um novo olhar para esses cidadãos participantes do Programa, sobretudo no que diz respeito aos processos de conscientização social. Isso principalmente no que se refere às questões de acesso ao esporte e ao lazer, visto que até então, para essas populações atendidas pelo Programa, esses direitos sociais não tinham sido atendidos, o que muitas vezes se deve por estas comunidades ficarem distantes dos centros urbanos e tornarem-se geograficamente excluídas, e ainda, algumas não tinham conhecimento de que o esporte e o lazer eram direitos constitucionais.

A temática sobre as comunidades quilombolas e rurais se fez presente nas entrevistas dos cinco participantes, através das falas compostas sobre o que conheciam destas populações. Para Jaqueline, Laura e Yara, era um campo totalmente desconhecido, tanto de trabalho como de vivências pessoais: "não tinha conhecimento algum sobre estas comunidades antes de trabalhar no PELC ${ }^{8}$ (Yara). Já Deise conhecia uma comunidade quilombola e Fernando era oriundo de uma cidade do interior.

Esse desconhecimento sobre as comunidades em questão transformou-se em estímulo para os acadêmicos Deise, Fernando e Jaqueline ao buscarem atuar como agentes sociais no PELC/PCT/UFSM, como demonstrado por Jaqueline: "a minha busca por participar do PELC foi em função de me sentir desafiada em poder trabalhar com estas comunidades, sendo um público diferenciado do que estava acostumada".

Essa diferença em atuar nas comunidades rurais e quilombolas pode ser esboçada através do estudo de Lifschitz (2008), que traz a questão das particularidades apresentadas dentro dos universos culturais dos quilombolas, onde os mesmos mantêm culturas próprias dentro de seus territórios. Assim, consequentemente, quem não conhece e vai adentrar nessa realidade necessita buscar conhecimentos e adequar-se as suas culturas.

No caso de Laura e Yara, o caminho que as levou a participar do Programa se diferenciou dos demais por apresentarem sua motivação no âmbito de terem a possibilidade de levar a estas comunidades seus direitos sociais ao esporte e lazer através do PELC/PCT/UFSM, como retrata Yara: "minha motivação deu-se por poder levar as atividades de esporte e lazer até estas comunidades que geralmente a gente sabe que ficam de lado e não têm acesso a seus direitos ao esporte e lazer”. Este fato citado pelas acadêmicas acabou por ser confirmado durante a imersão destes cinco acadêmicos nas comunidades rurais e quilombolas em que atuaram como agentes sociais, uma vez que, ao serem arguidos durante as entrevistas sobre a presença das Políticas Públicas de Esporte e Lazer (PPEL) nas comunidades em que atuaram, foi apresentada, de forma unânime, a ausência das mesmas nestas comunidades.

8 O termo PELC quando mencionado através dos trechos retirados das falas dos acadêmicos faz referência ao PELC/PCT/UFSM. 
Corrobora Moreira (2008), ao explanar que as políticas públicas para o meio rural não são ofertadas pelo poder público da mesma forma que para a população urbana, ficando, por muitas vezes, o meio rural sem o acesso aos seus direitos básicos de cidadãos (saúde, educação, entre outros). Um dos propósitos do PELC/PCT/UFSM era fazer com que esses cidadãos atendidos pelo Programa tomassem conhecimento sobre esse direito social e tivessem acesso às PPEL, e os agentes sociais foram fundamentais para atender essa demanda, como relata Fernando:

Em minhas oficinas eu sempre debatia muito com eles a questão de reivindicarem a oferta das PPEL junto ao poder público, porque todas as minhas turmas não sabiam que tinham esse direito, aí sempre batia nessa tecla que tinham direito e deveriam reivindicar junto ao poder público. (Fernando)

Como corrobora Sawitzki (2012, p.5), “a garantia do oferecimento da prática esportiva e do lazer ao cidadão é dever do poder público, sendo direito constitucional que deve ser oportunizado através de políticas públicas $[\ldots] ”$.

Outros dois fatores, também apresentados com unanimidade pelos acadêmicos frente as suas atuações nas comunidades rurais e quilombolas, foram em relação à maior receptividade dada pelas comunidades rurais e às dificuldades de deslocamento até essas comunidades.

Em relação ao exposto anteriormente, essas vivências promovidas através da prática e caracterizadas como os saberes experienciais (TARDIF, 2014) podem ser oriundas dos espaços escolares, tanto dos formais como dos informais. Como nos traz Krug (2001, p.41):

O ensino intelectualizado de aula ou mesmo de laboratório, precisa estar contextualizado, referido no real, quer sob a forma de atividade, de trabalho prático [...] onde surge a extensão como uma importante ferramenta institucional com a finalidade de complementar o currículo.

No que se refere aos saberes experienciais na formação do professor, Farias, Shigunov e Nascimento (2001, p. 27) ressaltam que "durante o período de formação inicial, torna-se importante que o aluno tenha o contato com a realidade em que futuramente irá atuar [...]”. Essa imersão na realidade das comunidades é discutida por Falcão (2006, p. 34):

Esse fluxo, que estabelece a troca de saberes sistematizados, acadêmicos e populares, terá como consequência a produção do conhecimento resultante do confronto com a realidade brasileira e regional, a democratização do conhecimento acadêmico e a participação efetiva da comunidade na atuação da universidade.

Quando os agentes sociais são questionados diretamente sobre os legados da atuação no PELC/PCT/UFSM frente à formação inicial, destacam-se os relatos sobre a relevância dos conhecimentos 
teóricos e práticos adquiridos com a atuação nessas comunidades, como retratado por Deise: "ter participado como agente social do Programa me proporcionou o aprendizado de muitos conhecimentos profissionais e até mesmo pessoais através da oportunidade de trabalhar com os quilombolas e rurais $[\ldots] ”$.

As explanações das entrevistadas Jaqueline, Deise e Laura destacaram que a partir de sua participação no PELC/PCT/UFSM aprenderam a enfrentar desafios impostos pelas diferentes realidades em que o Programa estava inserido, levando-as a constatar que somente os conhecimentos adquiridos através do currículo da graduação não eram suficientes, pois em suas práticas percebiam a necessidade de buscar outros conhecimentos além dos ensinados na sala de aula. Como destaca Jaqueline nesse trecho de sua entrevista:

\begin{abstract}
Aprendi a enfrentar desafios e vencer vários medos na hora de desenvolver minhas oficinas [...], acabei aprendendo com o PELC que para ser professor só os conhecimentos acadêmicos que a graduação já tinha me passado não bastava sabe, pois sempre tinha que buscar coisas novas para que tivesse sucesso nas oficinas e também saber como agir se o plano não desse certo tinha sempre que ter uma carta na manga, e isso me ensinou a encarar a realidade de ser uma professora mesmo [...]. (Jaqueline)
\end{abstract}

Deste modo, esses fatos colocados pelas acadêmicas vão ao encontro do que trata Tardif (2014) quando menciona que, no exercício cotidiano da sua profissão, o professor se depara com situações concretas que exigem improvisação e habilidades pessoais, estas que só são desenvolvidas nas práticas, passando despercebidas pelos saberes adquiridos na sua formação.

Outro aspecto importante mencionado por uma das entrevistadas foi a necessidade de respeitar a individualidade das pessoas e agir conjuntamente com seus alunos, como mostra o fragmento a seguir:

Aprendi a respeitar a individualidade de cada pessoa ao realizar exercícios físicos, fato que a graduação não nos passa essa ideia, só nos ensina a trabalhar com um corpo e assim com essa ideia na prática a gente se frustra, pois ninguém é igual ao outro e isso o PELC me ensinou, que a gente tem que trabalhar as atividades em conjunto com nossos alunos. (Yara)

Assim como o exposto por Yara, quanto à importância da interação entre alunos e professor, Tardif (2014, p.50) revela que essas interações exigem do professor "não um saber sobre um objeto de conhecimento, mas a capacidade de se comportar como sujeito, como ator e de ser uma pessoa em interação com outras pessoas”. Na mesma direção, Castilhos, Castro e Camargo (2019, p. 124) apontam que as experiências ocupam um papel central na formação, "estabelecendo relações com o contexto de atuação e potencializando um exercício de autorreflexão e ressignificação de valores e crenças em relação ao "tornar-se professor"”. 
Já para Fernando, a sua atuação no Programa no que se refere à formação enquanto professor de Educação Física foi ainda mais longe, pelo fato de que o PELC/PCT/UFSM the proporcionou um novo campo de trabalho com grupos de pessoas idosas, como destacado no segmento abaixo:

[...] participar do PELC foi um divisor de águas na minha formação, porque nunca tinha pensado e nem sabia nada também né sobre a terceira idade, mas no PELC trabalhei com muitos grupos e acabei ganhando os grupos de terceira idade como um novo campo de trabalho, pois atualmente trabalho com alguns grupos do tempo do Programa que me pediram pra continuar dando ginástica pra eles depois que o projeto terminou [...]. (Fernando).

Esse campo de atuação e de conhecimentos adquiridos por Fernando, advindo de sua ação extencionista no PELC/PCT/UFSM, reforça o exposto por Rechia, Tschoke e Moro (2012), que destacam que a extensão universitária possibilita aos professores e alunos qualificar suas ações pedagógicas.

\section{Considerações finais}

No decorrer do desenvolvimento dessa pesquisa pode-se refletir e compreender aspectos importantes da construção da identidade profissional de professor de Educação Física. Foram vários os caminhos trilhados, muitos desafios e diferentes visões de mundo, olhares diversos e de lugares incomuns, mas que em algum momento se cruzaram. SER professor de Educação Física, que ser é esse? Ser humano, ser compreensivo, ser parceiro, ser inteligente, ser humilde, ser dinâmico, ser atleta, ser amigo, ser pedagógico, ser político, ser alegre, ser disponível... Como ser tudo isso?

Percebe-se que a atuação em projetos sociais constitui-se em um momento de superação de obstáculos, conhecimento de realidades diferenciadas, de trocas, de diálogos, reflexões e aprendizados. É o momento de vivenciar a docência, tendo embasamento teórico e pedagógico para atuar de forma responsável, comprometida e competente, proporcionando aos acadêmicos a construção de sua identidade profissional e seu caminho no ensino da Educação Física.

A ligação entre universidade e comunidade demonstra um convívio em que há trocas de conhecimentos e experiências, auxiliando na qualificação e amadurecimento profissional através das intervenções. E a comunidade pode usufruir o que é um direito constitucional no que se refere às políticas públicas de esporte e lazer.

A partir das reflexões expostas anteriormente, percebe-se a necessidade de desenvolver durante o processo formativo a interligação entre o aprendizado acadêmico e a realidade social vivida fora deste âmbito.

A participação nas ações do PELC/PCT/UFSM proporcionou experiências e vivências, constituiuse um momento de relacionar os conhecimentos acadêmicos com a realidade a qual é muito diferenciada, 
pois, segundo os relatos, durante a graduação, no que se refere a essas comunidades e seus direitos (comunidades rurais e quilombolas), os acadêmicos não foram contemplados.

Acreditamos, assim, que atuar em um programa com as especificidades do PELC/PCT/UFSM só foi possível devido ao incentivo e apoio do CEFD, através de questões administrativas e de estrutura, e, além disso, podendo contar com professores comprometidos e competentes, capazes de instigar, motivar e proporcionar condições para um aprendizado significativo, de mudanças nas concepções de cultura e valores para a vida.

Tudo que foi exposto até aqui nos conduz para outro caminho a ser percorrido. SER professor é estar permanentemente percorrendo caminhos... Em busca de novos conhecimentos, de novos desafios, novas situações, uma busca incessante e apaixonante pelo incerto certo ou pelo certo incerto.

\section{Referências}

BRASIL. Ministério da Educação, Conselho Nacional de Educação (2002). Resolução CNE/CP 1 de 18 de fevereiro de 2002 - Institui a duração e a carga horária dos cursos de licenciatura, de graduação plena, de formação de professores da Educação Básica em nível superior. Disponível em: http://portal.mec.gov.br/cne/arquivos/pdf/rcp01_02.pdf. Acesso em: 10 de março de 2018.

BRASIL. Ministério do Esporte. Diretrizes do Programa Esporte e Lazer da Cidade, 2012. Disponível em: http://www.esporte.gov.br/arquivos/snelis/PELC2012/diretrizesEdital2012V4.pdf. Acesso em: 15 de maio de 2018.

CARREIRO DA COSTA, F. A. A. Formação de Professores: objetivos, conteúdos e estratégias. Revista da Educação Física/UEM, Maringá, 5 (1): 26-39, 1994.

CASTIlHOS, R. L.; CASTRO, F. B. de; CAMARGO, M. C. da S. Rev. Eletrônica Pesquiseduca. Revista do Programa de Educação Universidade Católica de Santos, EDUL. v. 11, n. 23, p.114-126, 2019.

CHAVES, M.; GAMBOA, S. S. A Relação Universidade e Sociedade: A "Problematização" nos Projetos Articulados de Ensino, Pesquisa e Extensão. ETD - Educação Temática Digital, Campinas, v.10, n.1, p.144-167, dez. 2008. Disponível em: www.fae.unicamp.br/revista. Acesso em: 05 de setembro de 2019.

FALCÃO, E. F. Vivência em comunidade: outra forma de ensino. João Pessoa: Editora Universitária/UFPB, 2006.

FARIAS, G. O.; SHIGUNOV, V.; NASCIMENTO, J. V. do. Formação e Desenvolvimento. In: SHIGUNOV, V.; SHIGUNOV NETO, A. (Orgs.). A Formação Profissional e a Prática Pedagógica: ênfase nos professores de Educação Física. Londrina, PR: O Autor, 2001.

FRANCO, M. L. P. B. Análise de conteúdo. 4. ed. Brasília: Editora Liber Livro, 2012.

GIL, A. C. Como elaborar projetos de pesquisa. São Paulo: Atlas, 1987.

KRUG, H. N. Formação de Professores Reflexivos: ensaios e experiências. Santa Maria: O autor, 2001. 
LIFSCHITZ, J. A. Percursos de uma neocomunidade quilombola: entre a "modernidade" afro e a "tradição" pentecostal. Revista Afro-Asia, Salvador, n. 37, p. 153-174, 2008. Disponível em: www.portalseer.ufba.br/index.php/afroasia/article/view/21156. Acesso em: 16 de janeiro de 2020.

MARTINS, G. A. Estudo de Caso: uma estratégia de pesquisa. São Paulo: Atlas, 2006.

MINAYO, M. C. de S. Pesquisa social: teoria, método e criatividade. 31. ed. Petrópolis, RJ: Vozes, 2012.

MOREIRA, F. Identidade cultural e cultura na fronteira homem/meio rural. Repositório da UFSC. 2008. Disponível em: www.rizoma.ufsc.br/pdfs/765-of10c-st1.pdf. Acesso em: 02 julho de 2019.

RECHIA, S.; TSCHOKE, A.; MORO, L. Espaço Univer-cidade e PELC: a experiência do grupo GEPLEC/UFPR na gestão do Programa Esporte e Lazer na Cidade de Curitiba. Revista Licere, Belo Horizonte, v. 15, n.1, mar. 2012.

SAWITZKI, R. L. Políticas Públicas para Esporte e Lazer: para além do calendário de eventos esportivos. Revista Licere, Belo Horizonte, v.15, n.1, mar. 2012.

SOUZA, C. Políticas Públicas: uma revisão da literatura. Sociologias [online]. N. 16, p. 20-45, 2006.

TARDIF, M. Saberes Docentes e Formação Profissional. 17. ed. Petrópolis-RJ: Vozes, 2014.

TONDIN, G. A formação dos educadores sociais de esporte e lazer no Programa Esporte e Lazer da Cidade - PELC - em Porto Alegre. 2011. Dissertação (Mestrado em Ciências do Movimento Humano)

- Escola de Educação Física - Universidade Federal do Rio Grande do Sul, Porto Alegre, RS, 2011.

UFSM. Universidade Federal de Santa Maria. Plano Desenvolvimento Institucional 2016 - 2026. Santa Maria, 2016. Disponível em: https://www.ufsm.br/app/uploads/sites/500/2018/12/00-DocumentoPDITextoBaseCONSU.pdf. Acesso em: 21 de agosto de 2020.

\section{Como citar este artigo}

RAZEIRA, T. R.; CASTILHOS, R. L.; SILVA, S. D.; QUADROS, R. B.; SAWITZKI, R. L. O PELC-Povos e comunidades tradicionais e a formação de professores do CEFD. Revista Kinesis, Santa Maria, Dossiê CEFD 50 anos, p.01-12, 2020.

*O presente trabalho foi realizado com apoio da Coordenação de Aperfeiçoamento de Pessoal de Nível Superior - Brasil (CAPES) - Código de Financiamento 001 